Supporting Information for

\title{
Promoting Effect of Heterostructured NiO/Ni on Pt Nanocatalysts toward Catalytic Hydrolysis of Ammonia Borane
}

Xueying Ren, Hao Lv, Su Yang, Yingying Wang, Jinlong Li, Ren Wei, Dongdong Xu, and Ben Liu*

Jiangsu Key Laboratory of New Power Batteries, Jiangsu Collaborative Innovation Center of Biomedical Functional Materials, School of Chemistry and Materials Science, Nanjing Normal University, Nanjing 210023, China;

*Email: ben.liu@njnu.edu.cn 


\section{Chemicals and Materials}

Multi-walled Carbon nanotube (CNT) was obtained from Aladdin Industrial Corporation with the external diameter of 20-30 nm and the length of 500-2000 nm. Nickel(II) Acetate Tetrahydrate $\left(\mathrm{Ni}(\mathrm{Ac})_{2} \cdot 4 \mathrm{H}_{2} \mathrm{O}\right)$ and sodium borohydride $\left(\mathrm{NaBH}_{4}\right)$ were purchased from Shanghai Titanchem Co. Ltd. N,N-Dimethylformamidel (DMF) and heavy water $\left(\mathrm{D}_{2} \mathrm{O}\right)$ were purchased from Sinopharm Chemical Reagent Co. Ltd. (Shanghai). Chloroplatinic acid hexahydrate $\left(\mathrm{H}_{2} \mathrm{PtCl}_{6} \cdot 6 \mathrm{H}_{2} \mathrm{O}\right)$ was purchased from Adamas Reagent Co. Ltd. Ammonia borane (AB) complex was purchased from Nine-Dinn Chemistry Co. Ltd. (Shanghai). All the reagents are of analytical reagent grade and used without further purification. Deionized $\mathrm{H}_{2} \mathrm{O}$ with the resistivity of $18.25 \mathrm{~m} \Omega$ was used in all experiments.

\section{Synthesis details}

\subsection{Oxidation of multi-walled carbon nanotube (CNT)}

Multi-walled carbon nanotubes (CNTs) were oxidized according to a modified Hummers method (Nat. Commun. 2014, 5, 4695).

\subsection{NiO-CNT and NiO/Ni-CNT}

The NiO/CNT in this paper was synthesized on the basis of the method developed by Hongjie Dai's group (Nat. Commun. 2014, 5, 4695). Typically, $300 \mathrm{mg}$ of oxided multi-walled CNTs were sonicated in $600 \mathrm{~mL}$ of DMF for $30 \mathrm{~min}$, followed by the addition of $6 \mathrm{~mL}$ of $\mathrm{Ni}(\mathrm{Ac})_{2} \cdot 4 \mathrm{H}_{2} \mathrm{O}$ aqueous solution $(0.2 \mathrm{M})$. After sonicated for another $30 \mathrm{~min}$, the solution was vigorously stirred at $90{ }^{\circ} \mathrm{C}$ for $4 \mathrm{~h}$. The mixture solution was cooled to room temperature naturally, and the product was centrifuged and washed with deionized water for three times. The obtained precipitate was then dried at freezer dryer overnight. The final sample was calcined in the $\mathrm{N}_{2}$ gas at $300{ }^{\circ} \mathrm{C}$ for $1 \mathrm{~h}$ with the ramp of $1{ }^{\circ} \mathrm{C} \cdot \mathrm{min}^{-1}$ to form the NiO-CNT. Similarly, the NiO-CNT with different Ni contents were synthesized using the above procedures by simply changing $\mathrm{Ni}(\mathrm{Ac})_{2} \cdot 4 \mathrm{H}_{2} \mathrm{O}$ aqueous solution contents.

NiO/Ni-CNT was synthesized by further calcination with $\mathrm{H}_{2} / \mathrm{N}_{2}$ gas (1:9) at $200{ }^{\circ} \mathrm{C}$ for $1 \mathrm{~h}$ with the ramp of 1 ${ }^{\circ} \mathrm{C} \cdot \mathrm{min}^{-1}$. Meanwhile, Ni-CNT was collected by $\mathrm{H}_{2} / \mathrm{N}_{2}$ calcination at $600{ }^{\circ} \mathrm{C}$. Besides, NiO/Ni-CNT with different $\mathrm{NiO} / \mathrm{Ni}$ ratios were obtained at different calcination temperatures $\left(\mathrm{H}_{2} / \mathrm{N}_{2}\right)$.

\subsection{Pt@Ni/NiO-CNT, Pt@NiO-CNT and Pt@Ni-CNT}

Ultrasmall Pt nanoparticles (NPs) were grown on the NiO/Ni-CNT through ultrasound assisted incipient wetness impregnation of $\mathrm{H}_{2} \mathrm{PtCl}_{6} \cdot 6 \mathrm{H}_{2} \mathrm{O}$ solution in ethanol and further gas phase reduction under $\mathrm{H}_{2} / \mathrm{N}_{2}$ atmosphere at 200 ${ }^{\circ} \mathrm{C}$ for $1 \mathrm{~h}$ (J.Am. Chem. Soc. 2012, 134, 20457). Typically, $10 \mathrm{mg}$ of NiO/Ni-CNT (or Pt@Ni-CNT) was added to $2 \mathrm{~mL}$ of ethanol for $10 \mathrm{~min}$. Then, $0.5 \mathrm{~mL}$ of $\mathrm{H}_{2} \mathrm{PtCl}_{6} \cdot 6 \mathrm{H}_{2} \mathrm{O}\left(0.5 \mathrm{mg} \mathrm{ml}^{-1}\right)$ was added. After stirred for $30 \mathrm{~min}$, the ethanol was thoroughly evaporated at $60^{\circ} \mathrm{C}$ for $2 \mathrm{~h}$. The collected powder was then transferred to tube furnace, and calcined under $\mathrm{H}_{2} / \mathrm{N}_{2}$ atmosphere at $200{ }^{\circ} \mathrm{C}$ for $1 \mathrm{~h}(\mathrm{Pt} @ \mathrm{NiO} / \mathrm{Ni}-\mathrm{CNT})$. Similarly, Pt@Ni-CNT can be obtained.

In contrast, Pt@NiO-CNT was synthesized by in situ reduction by $\mathrm{NaBH}_{4}$. In a typical synthesis, $10 \mathrm{mg}$ of $\mathrm{NiO} / \mathrm{CNT}$ powders were sonicated in $10 \mathrm{ml}$ deionizd $\mathrm{H}_{2} \mathrm{O}$ for $60 \mathrm{~min}$, followed by the addition of $0.5 \mathrm{~mL}$ of 
$\mathrm{H}_{2} \mathrm{PtCl}_{6} \cdot 6 \mathrm{H}_{2} \mathrm{O}$ aqueous solution $\left(0.5 \mathrm{mg} \mathrm{ml}^{-1}\right)$. After vigorously stirred for $60 \mathrm{~min}, 1 \mathrm{~mL}$ of freshly prepared and ice-cooled $\mathrm{NaBH}_{4}$ solution $\left(2 \mathrm{mg} \mathrm{ml}^{-1}\right)$ was injected with vigorous stirring. The product was then centrifuged and washed with deionized $\mathrm{H}_{2} \mathrm{O}$ for three times.

\section{Catalytic hydrolysis of $\mathbf{A B}$}

The as-prepared samples (Pt@Ni/NiO-CNT, Pt@NiO-CNT and Pt@Ni-CNT) were applied as the catalysts for the room-temperature hydrolysis of $\mathrm{AB}$. The production of $\mathrm{H}_{2}$ gas was periodically recorded by reading the volumes against discharged $\mathrm{H}_{2} \mathrm{O}$ at regular intervals through a classic $\mathrm{H}_{2} \mathrm{O}$-displacement method. Typically, the catalyst containing $0.116 \mathrm{mM}$ of Pt NPs was dispersed in $3 \mathrm{~mL}$ of $\mathrm{H}_{2} \mathrm{O}$ and then sonicated for $10 \mathrm{~min}$ to obtain a uniformly dispersed solution. The hydrolysis reaction of $\mathrm{AB}$ started rapidly when $4 \mathrm{~mL}$ of $5 \mathrm{mg} \mathrm{mL}^{-1} \mathrm{AB}$ was injected into above solution at $298 \mathrm{~K}$. The reaction thermodynamics of $\mathrm{AB}$ hydrolysis was investigated by varying test temperature at 293, 303, 308 and $313 \mathrm{~K}$, while the kinetics of AB hydrolysis was studied through changing the concentration of $\mathrm{Pt}(0.0579,0.116,0.174$ and $0.232 \mathrm{mM})$ and the content of $\mathrm{AB}(16,20,24$, and $18 \mathrm{mg})$. For the durability measurements of the catalysts, the hydrolysis of $\mathrm{AB}$ was repeated 5 times by adding another equivalent of $\mathrm{AB}(5 \mathrm{mg} \mathrm{mL}-1,4 \mathrm{~mL})$ into the reaction mixture after complete conversion of $\mathrm{AB}$ at previous cycle.

\section{Characterizations}

TEM and high-resolution TEM studies were collected using a JEOL 2100 TEM with an accelerating voltage of 200 $\mathrm{kV}$. HAADF-STEM and corresponding line scans were performed on FEI Talos F200X apparatuses equipped with STEM and EDS detectors. TEM and STEM samples were prepared by casting a suspension of the samples (in $\mathrm{H}_{2} \mathrm{O}$ ) on a carbon coated copper grid (300 mesh). $\mathrm{H}_{2}$-TPR was recorded in an Auto-Chem 2920 instrument. XRD patterns (both small-angle and wide-angle) were carried out on powder samples using a D/max $2500 \mathrm{VL} / \mathrm{PC}$ diffractometer (Japan) equipped with graphite-monochromatized $\mathrm{Cu} \mathrm{K \alpha}$ radiation. XPS was collected on a scanning X-ray microprobe (Thermo ESCALAB 250Xi) that uses Al Ka radiation, and C 1s peak (284.8 eV) was employed as a standard to calibrate the binding energies of other elements. Inductively coupled plasma atomic emission spectroscopy (ICP-AES) was recorded on a NexION 350D.

\section{CO stripping test}

CO stripping tests were carried out according to our previous work (ACS Cent. Sci. 2018, 4, 1412). Typically, the work electrode containing $3.0 \mu \mathrm{g}$ of the catalyst was immersed in $1 \mathrm{M} \mathrm{KOH}$ solution. Then, $\mathrm{CO}$ was purged in the solution for $30 \mathrm{~min}$ to achieve the maximum coverage of $\mathrm{CO}$ at a fixed potential of $0.15 \mathrm{~V}$ (SCE). After that, the electrode was moved into fresh $\mathrm{N}_{2}$-purged 1.0 M KOH solution for $\mathrm{CO}$ stripping measurements. $\mathrm{CO}$ stripping voltammetry was recorded in the potential range between -0.9 and $0.2 \mathrm{~V}$ at a scan rate of $50 \mathrm{mV} \mathrm{s}^{-1}$. 

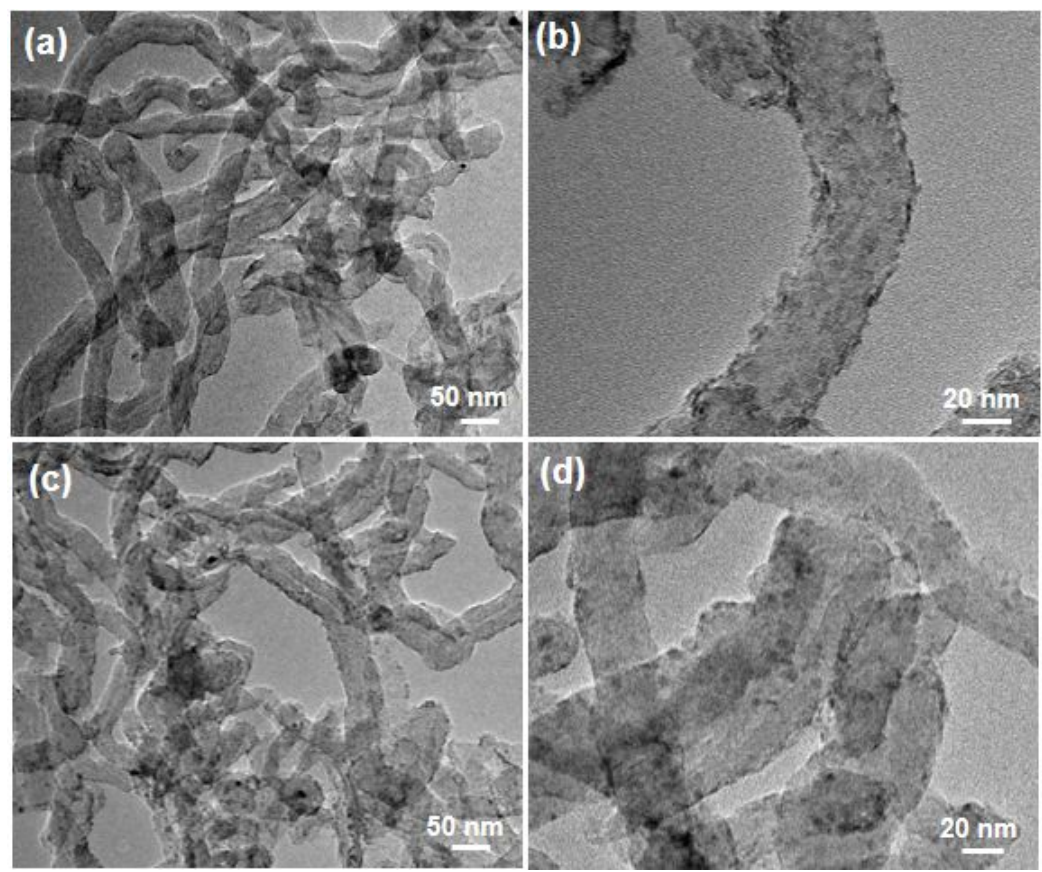

Figure S1. TEM images of $(a, b) \mathrm{NiO}-\mathrm{CNT}$ and $(\mathrm{c}, \mathrm{d}) \mathrm{NiO} / \mathrm{Ni}-\mathrm{CNT}$.
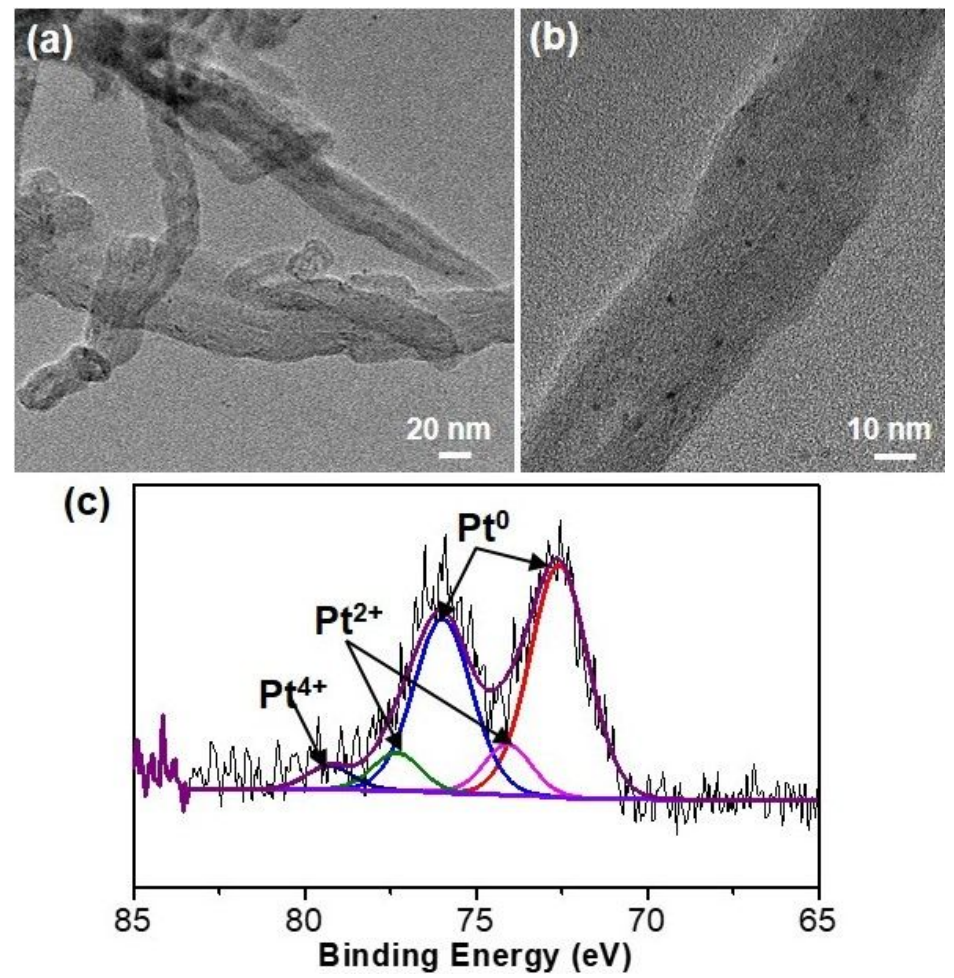

Figure S2. $(\mathrm{a}, \mathrm{b})$ TEM images and (c) high-resolution XPS Pt 4f of the Pt@CNT, indicating ultrasmall Pt NPs were grown in situ on the surface of CNT. 

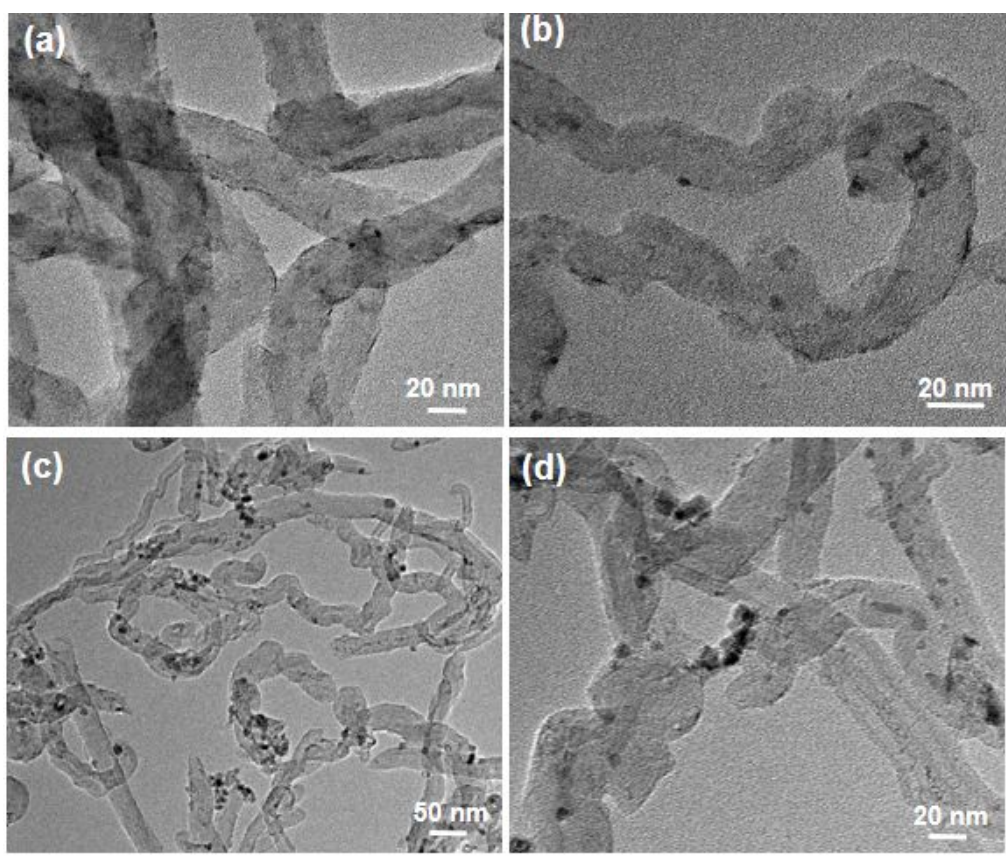

Figure S3. TEM images of (a, b) Pt@NiO-CNT and (c, d) Pt@Ni-CNT.

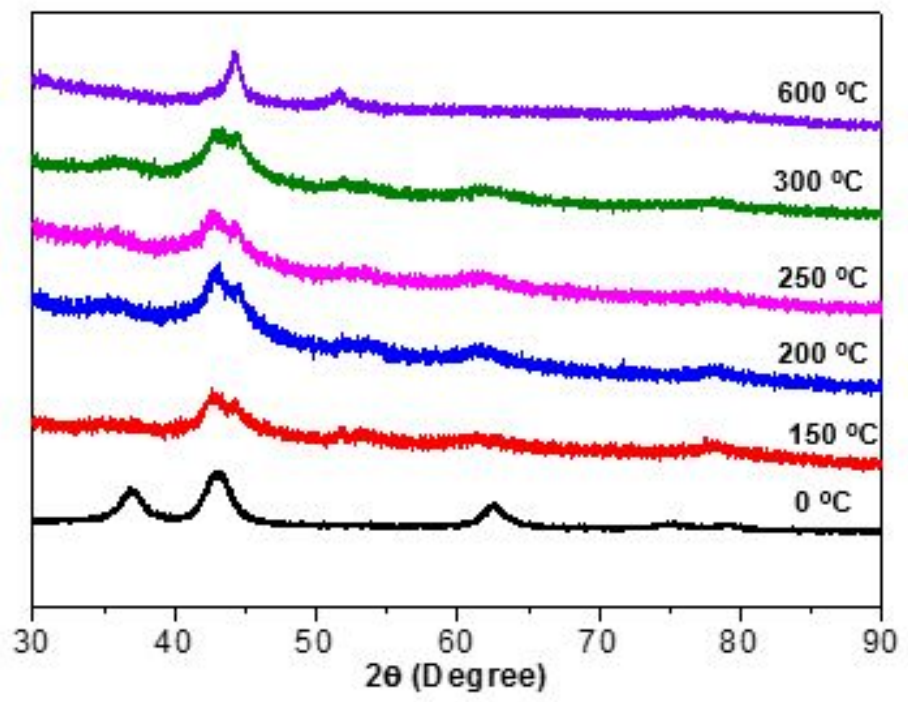

Figure S4. XRD patterns of the Pt@NiO/Ni-CNT with different NiO/Ni amounts. The samples were obtained under different $\mathrm{H}_{2} / \mathrm{N}_{2}$ treatment temperatures, indicating that the higher temperature gave rise to a higher amount of metallic Ni. 


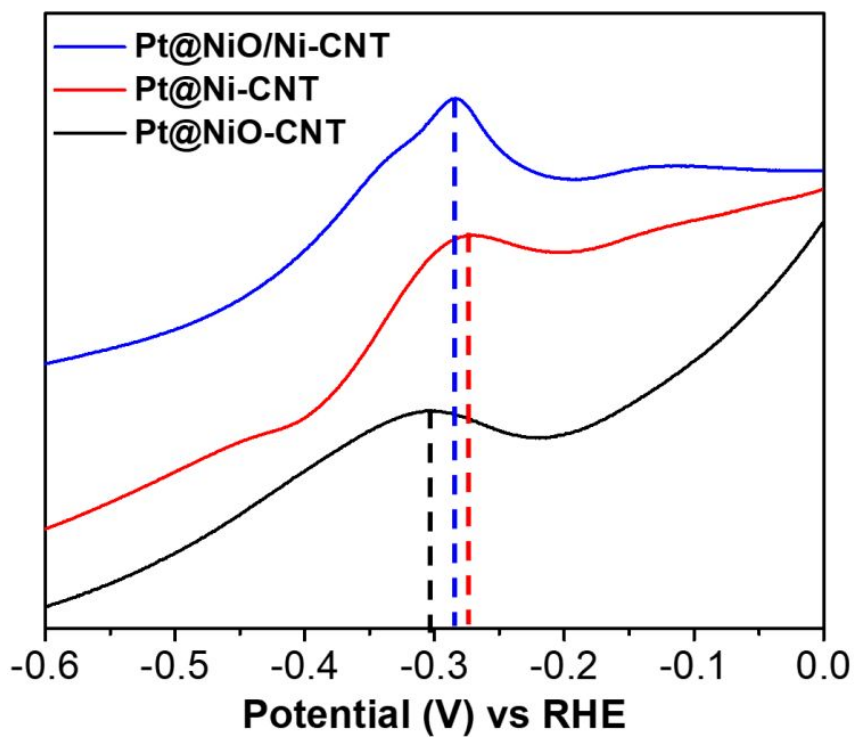

Figure S5. CO stripping voltammetry of the Pt@NiO/Ni-CNT, Pt@Ni-CNT, and Pt@NiO-CNT collected in the potential range of -0.6 and $0 \mathrm{~V}$ (vs RHE).
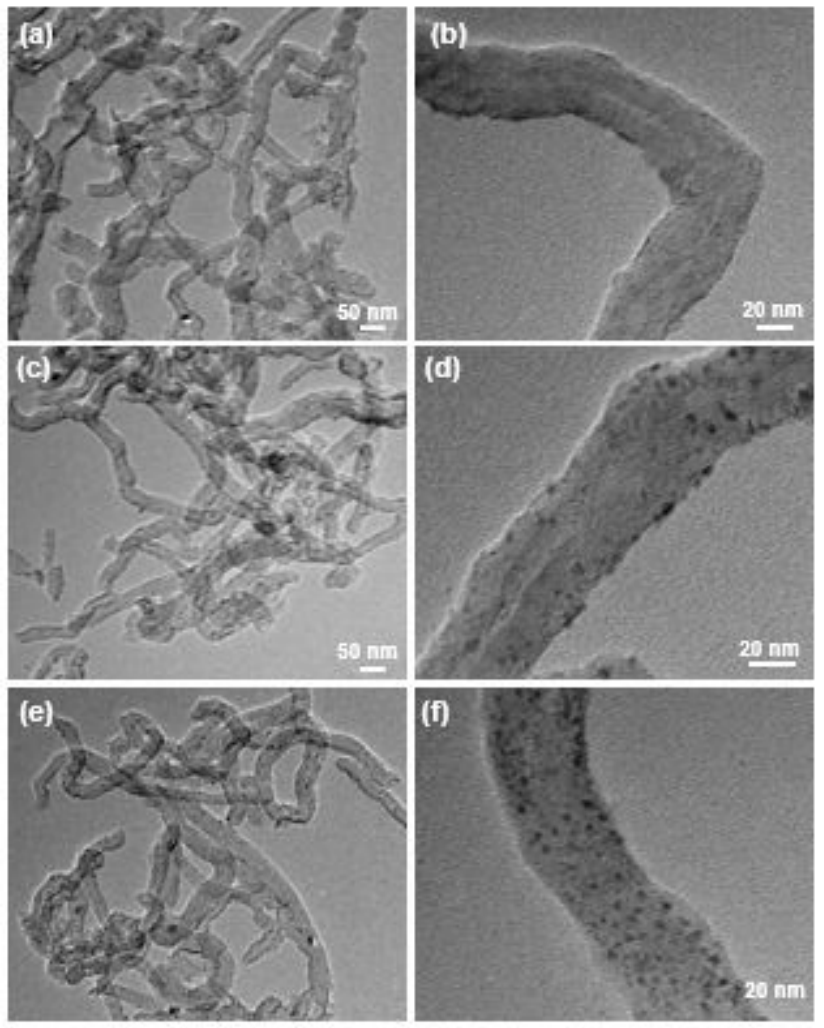

Figure S6. TEM images of the $\mathrm{Pt} @ \mathrm{NiO} / \mathrm{Ni}-\mathrm{CNT}$ with different $\mathrm{NiO} / \mathrm{Ni}$ amounts. The samples were obtained under different $\mathrm{H}_{2} / \mathrm{N}_{2}$ calcination temperature of $(\mathrm{a}, \mathrm{b}) 150^{\circ} \mathrm{C}$, (c, d) $250{ }^{\circ} \mathrm{C}$, and (e, f) $300{ }^{\circ} \mathrm{C}$. 


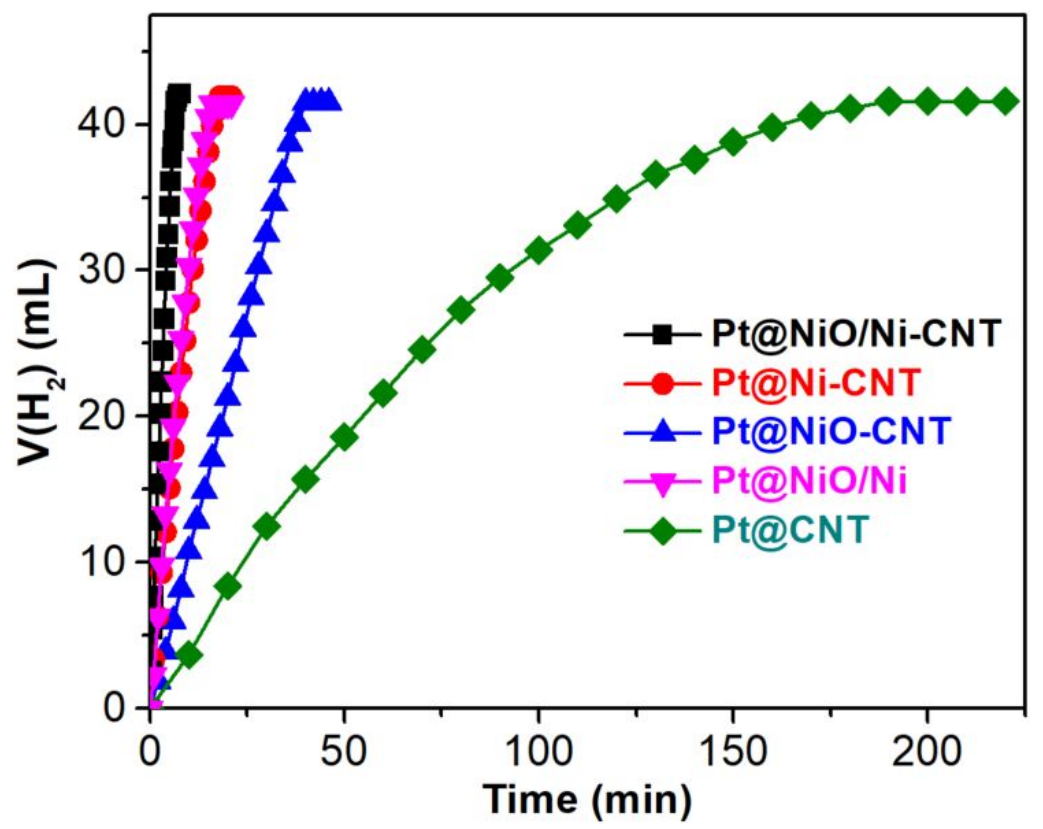

Figure S7. (a) $\mathrm{H}_{2}$ volume produced vs. the reaction time for the hydrolysis of $\mathrm{AB}$ over the $\mathrm{Pt} @ \mathrm{NiO}-\mathrm{CNT}, \mathrm{Pt} @ \mathrm{NiO} / \mathrm{Ni}-$ CNT,Pt@Ni-CNT,Pt@NiO/Ni, andPt@CNT.

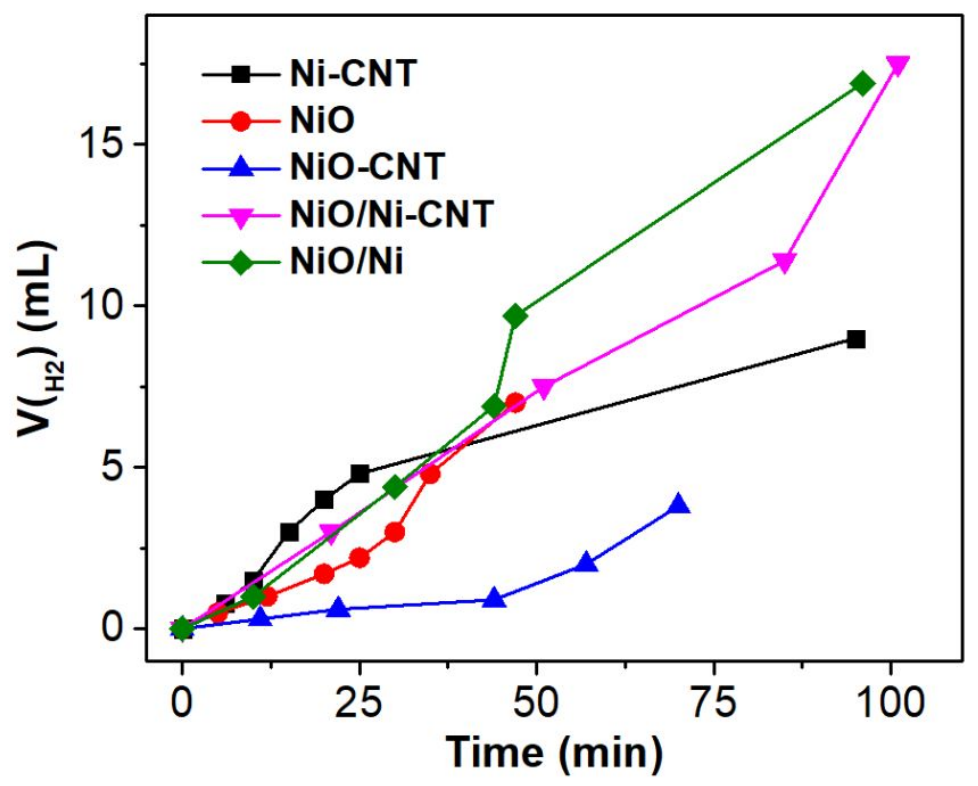

Figure S8. (a) $\mathrm{H}_{2}$ volume produced $v s$. the reaction time for the hydrolysis of $\mathrm{AB}$ over $\mathrm{Ni}-\mathrm{CNT}, \mathrm{NiO}, \mathrm{NiO}-\mathrm{CNT}, \mathrm{NiO} / \mathrm{Ni}-$ $\mathrm{CNT}$, and $\mathrm{NiO} / \mathrm{Ni}$. Catalytic performance of the $\mathrm{Ni}-\mathrm{CNT}$ and $\mathrm{NiO}$ was carried out at $60{ }^{\circ} \mathrm{C}$, while others were tested at $35^{\circ} \mathrm{C}$. 

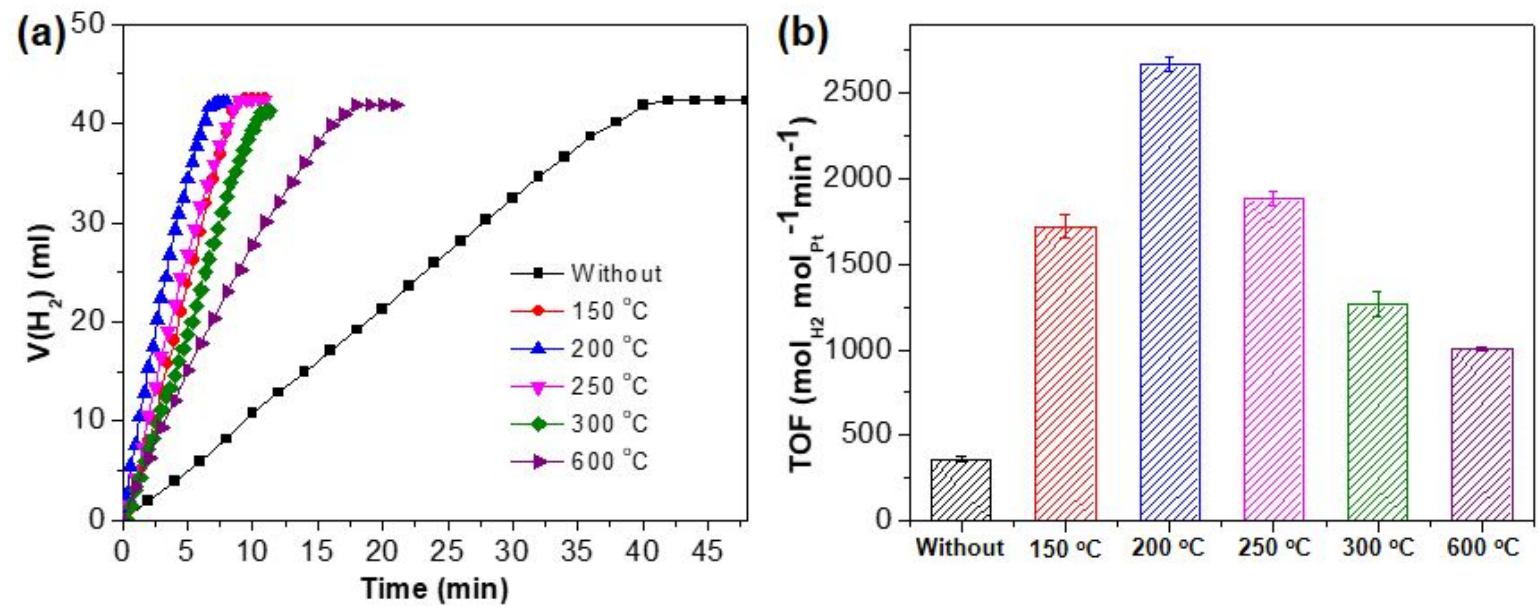

Figure S9. The AB hydrolysis activity over the Pt@NiO/Ni-CNT catalyst with different NiO/Ni ratios. (a) The relationship between $\mathrm{H}_{2}$ volume produced and reaction time and (b) calculated TOFs for the hydrolysis of $\mathrm{AB}$ over $\mathrm{Pt} @ \mathrm{NiO} / \mathrm{Ni}-\mathrm{CNT}$ without calcination and with $\mathrm{H}_{2} / \mathrm{N}_{2}$ calcination temperature of $150{ }^{\circ} \mathrm{C}, 200{ }^{\circ} \mathrm{C}, 250{ }^{\circ} \mathrm{C}, 300{ }^{\circ} \mathrm{C}$, and 600 ${ }^{\circ} \mathrm{C}$.
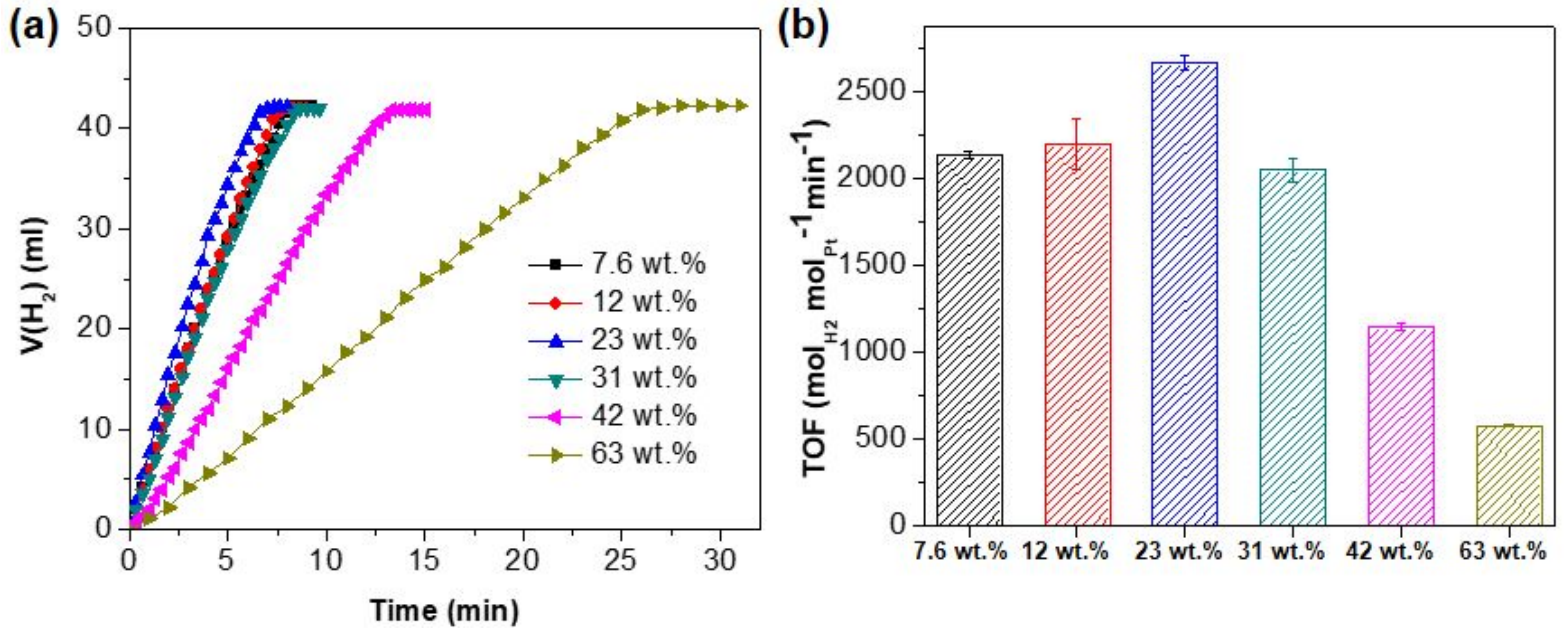

Figure S10. The AB hydrolysis activity over the $\mathrm{Pt} @$ aNiO/Ni-CNT catalyst with different NiO/Ni amounts. (a) The relationship between $\mathrm{H}_{2}$ volume produced and reaction time and (b) calculated TOFs for the hydrolysis of $\mathrm{AB}$ over Pt@NiO/Ni-CNT with total NiO/Ni amount of 7.6 wt. \%, 12 wt. \%, 23 wt. \%, 31 wt. \%, 42 wt. \% and 63 wt. \%. The Pt amount in all the samples was fixed to $\sim 1.0 \mathrm{wt}$. $\%$. 

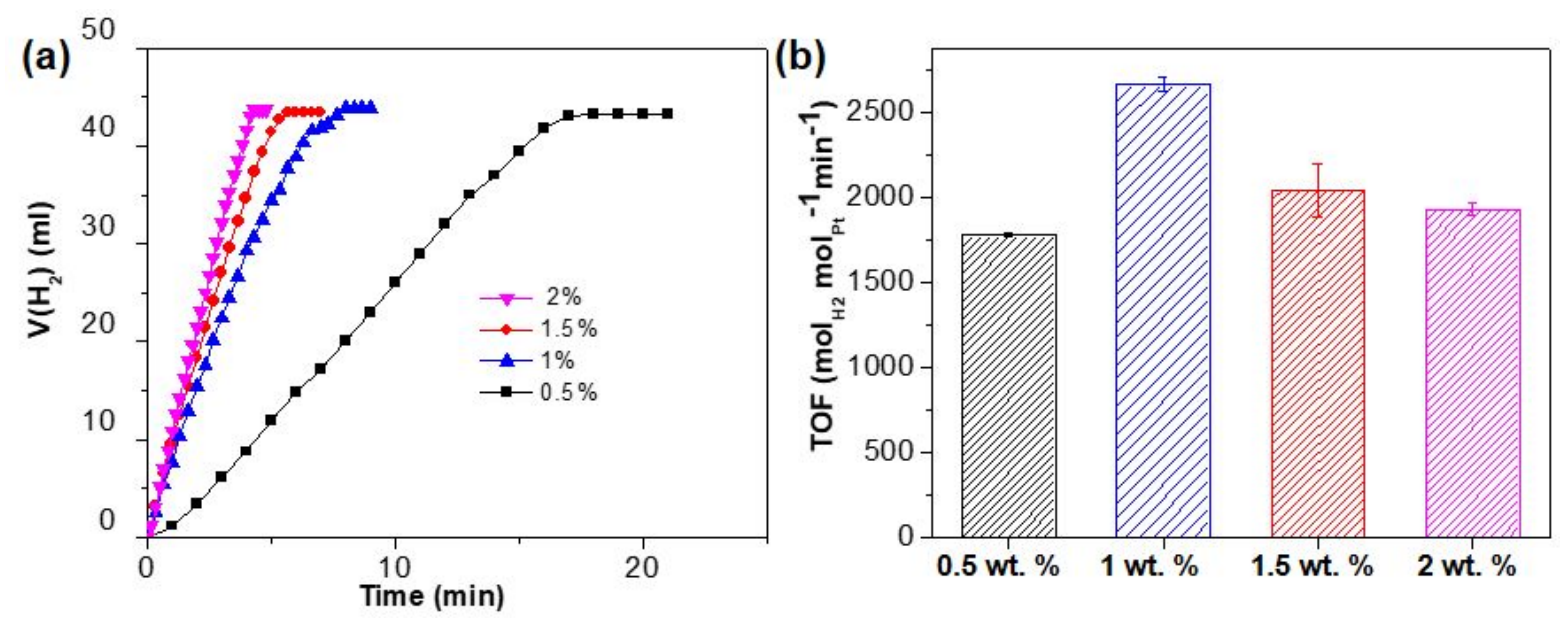

Figure S11. The AB hydrolysis activity over the Pt@NiO/Ni-CNT catalyst with different Pt loading amounts. (a) The relationship between $\mathrm{H}_{2}$ volume produced and reaction time and (b) calculated TOFs for the hydrolysis of $\mathrm{AB}$ over Pt@NiO/Ni-CNT with Pt loading amount of 0.5 wt. \%, 1 wt. \%, 1.5 wt. \%, and 2 wt. \%. The NiO/Ni amount in all the samples was fixed to 23 wt. \%.

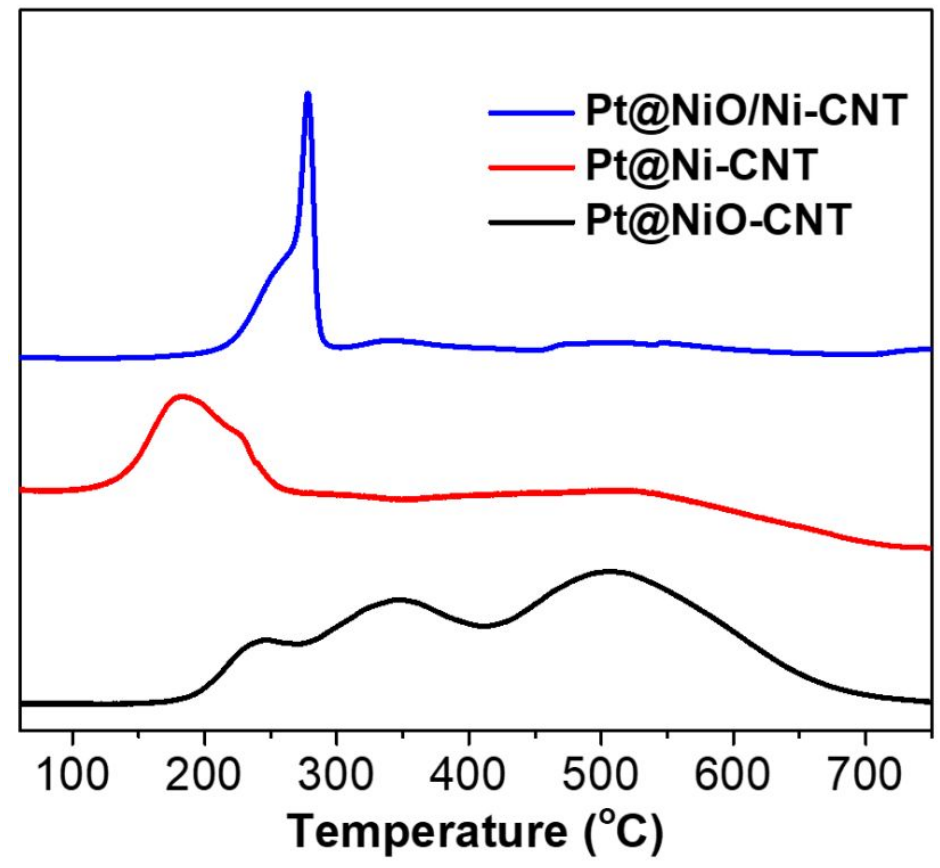

Figure S12. $\mathrm{H}_{2}-\mathrm{TPR}$ profiles of the Pt@NiO/Ni-CNT, Pt@Ni-CNT, and Pt@NiO-CNT. 
Table S1. Catalytic activities for AB hydrolysis catalyzed by the Pt-based heterogeneous catalysts.

\begin{tabular}{|c|c|c|c|c|}
\hline Catalyst & $\begin{array}{c}\text { Temperature } \\
\left({ }^{\circ} \mathrm{C}\right)\end{array}$ & $\begin{array}{c}\text { TOF } \\
\left(\mathrm{mol}_{\mathrm{H} 2} \mathrm{~mol}^{-1} \mathrm{~min}^{-1}\right)\end{array}$ & $\begin{array}{c}E_{a} \\
\left(\mathbf{k J} \cdot \mathrm{mol}^{-1}\right)\end{array}$ & References \\
\hline $\mathrm{Pt} @ \mathrm{NiO} / \mathrm{Ni}-\mathrm{CNT}$ & 25 & 2665.33 & 24.91 & This work \\
\hline Pt/CNT & 30 & 567 & -- & Chem. Commun. 2014, 50, 2142 \\
\hline Pt@MIL-101 & 25 & 414 & 40.7 & J. Am. Chem. Soc. 2012, 134, 13926 \\
\hline $\mathrm{PtCu}$ & 25 & $\begin{array}{c}859 \\
\text { (based on Pt) }\end{array}$ & $39 \pm 2$ & ChemCatChem 2017, 9, 4185 \\
\hline $\begin{array}{c}\mathrm{Pt}_{1} \mathrm{Co}_{1} \\
\text { (Dendrimer) }\end{array}$ & 20 & $\begin{array}{c}606 \\
\text { (based on Pt) }\end{array}$ & 28.8 & ACS Catal. 2019, 9, 1110 \\
\hline $\mathrm{PtCo}_{20} / \mathrm{CNTs}$ & 25 & 675.1 & 42.5 & Appl. Catal. B 2018, 235, 256 \\
\hline $\mathrm{Ni}_{2} \mathrm{Pt} @ Z \mathbf{Z I F - 8}$ & $\mathrm{rt}$ & $\begin{array}{c}\text { 600/2222.2 (based } \\
\text { on } \mathrm{Pt} \text { ) }\end{array}$ & 23.3 & J. Am. Chem. Soc. 2018, 140, 10034 \\
\hline $\mathrm{Pt}-\mathrm{CoCu} @ \mathrm{SiO}_{2}$ & 30 & $\begin{array}{c}272.8 \\
\text { (based on Pt) }\end{array}$ & -- & $\begin{array}{c}\text { ACS Sustainable Chem. Eng. 2017, 5, } \\
1675\end{array}$ \\
\hline 1/1000Pt+Ni/CNT & $\mathrm{rt}$ & 12000 & -- & ACS Catal. 2017, 7, 6762 \\
\hline PtNi@PVP & $\mathrm{rt}$ & $\begin{array}{c}511 / 638 \\
\text { (based on Pt) }\end{array}$ & -- & $\begin{array}{c}\text { ACS Appl. Mater. Interfaces 2014, } 6 \text {, } \\
12429\end{array}$ \\
\hline PtAuNi & 25 & 496 & -- & Nano Energy 2016, 23, 145 \\
\hline $\mathrm{PtNi} / \mathrm{NiO} @ \mathrm{SiO}_{2}$ & 30 & $\begin{array}{c}1240.3 \\
\text { (based on Pt) }\end{array}$ & -- & $\begin{array}{c}\text { ACS Appl. Mater. Interfaces 2017, 9, } \\
3749\end{array}$ \\
\hline Zn/Pt/RGO & 25 & 284 & -- & Nano Res. 2017, 10, 3811 \\
\hline${\mathrm{Pt25} @ \mathrm{TiO}_{2}}$ & 25 & 311 & -- & Angew. Chem. Int. Ed. 2016, 55, 12257 \\
\hline $\mathbf{P t} / \gamma-\mathrm{Al}_{2} \mathrm{O}_{3}$ & 25 & 222 & 21 & J. Power Sources 2007, 168, 135 \\
\hline $\mathrm{Pt} / \mathrm{CeO}_{2}$ & 25 & 182 & -- & Chem. Сотmun. 2012, 48, 10207 \\
\hline $\begin{array}{c}\mathrm{Pt}_{0.08} \mathrm{Co}_{0.92} / \\
\mathrm{Ti}_{3} \mathrm{C}_{2} \mathrm{X}_{2}\end{array}$ & 25 & $\begin{array}{c}727 \\
\text { (based on Pt) }\end{array}$ & 37.7 & New J. Chem. 2017, 41, 2793 \\
\hline Pt-MIL-101 & -- & 211.3 & 40.7 & J. Am. Chem. Soc. 2012, 134, 13926 \\
\hline $\mathrm{Co}_{0.32} @ \mathrm{Pt}_{0.68} / \mathrm{C}$ & -- & 147.6 & 41.5 & J. Power Sources 2011, 196, 2785 \\
\hline
\end{tabular}

